\title{
Longitudinal Spinal Organization with Segmental Dominance in Chinese Needle Therapy
}

\author{
Donald E. Kendall \\ Agoura Hills, CA, USA
}

\section{Keywords}

Needle therapy · Acupuncture · Propagated sensation . Organ-referred pain · Longitudinal organization . Segmental dominance $\cdot$ Treatment protocols

\section{Summary}

The Chinese called it 'needle therapy' which the West later interpreted as 'acupuncture' based on impossible ideas of energy and blood circulation via invisible meridians introduced in the late 1930s. Lack of understanding the original Chinese discoveries, which made needling a useful therapeutic approach, has made it difficult to correct these misconceptions. Willem ten Rhyne provided the first clues in 1683 that Chinese concepts involved continuous blood circulation and nerves. The oldest Chinese texts on blood vessel theory date to ca. 168-150 BC while needle therapy was introduced in the Yellow Emperor's Internal Classic (ca. 200-100 BC), along with a description of nerves. It introduced the ideas of longitudinal body organization along with segmental dominance that is fundamental to all vertebrates. The Chinese divided the body into 12 longitudinal regions on each side that contained the skeletal muscles, blood vessels, and neurovascular nodal pathway. Muscular distributions and nodal pathways were mapped out by observation of propagated sensation in sensitive responders to needling. Discovery of organ-referred pain led to understanding the role of spinal segmental dominance. Use of these features allowed development of repeatable treatment protocols using the concept of local and adjacent (segmental dominance), proximal, and distal nodes (longitudinal effects).

*Chinese characters and pīnyīn (拼 音) pronunciation guide terms: Classical Characters are used immediately before the simplified version after a back slash (/). The simplified characters are not repeated thereafter.

\section{KARGER

\section{Schlüsselwörter \\ Nadeltherapie · Akupunktur · Fortgeleitete Empfindung · \\ Fortgeleitete Organschmerzen · Longitudinale Organisation . \\ Segmentale Dominanz · Wiederholbare Behandlungsregeln}

\section{Zusammenfassung}

Longitudinale spinale Organisation mithilfe segmentaler Dominanz in der chinesischen Nadeltherapie

Was im Westen später als «Akupunktur» interpretiert worden ist und was im Europa der späten 1930er-Jahre des 20. Jahrhunderts auf unmögliche Vorstellungen von «Energie»-Flüssen und Blutzirkulation in unsichtbaren «Meridianen» zurückgeführt wurde, nannten die Chinesen ursprünglich «Nadeltherapie». Das im Westen fehlende Verständnis für ihre originalen Entdeckungen, die das Nadelstechen zu einer nützlichen Therapie werden liessen, macht es immer noch schwierig, derartige westliche Fehldeutungen zu korrigieren. Willem ten Rhyne gab schon 1683 erste Hinweise, dass die chinesischen Theorien die Blutzirkulation und die Nervenbahnen berücksichtigt hatten. Die ältesten chinesischen Texte zur Blutgefäss-Theorie stammen aus der Zeit um 168-150 v. Chr., während die Nadeltherapie im Inneren Klassiker des Gelben Kaisers (ca. 200-100 v. Chr.) mit einer Beschreibung von Nervenbahnen eingeführt wurde. Dies enthielt die Vorstellung einer longitudinalen Organisation mit segmentaler Dominanz, wie sie für alle Vertebraten massgebend ist. Die Chinesen teilten den menschlichen Organismus ein in 12 längsverlaufende Zonen aufjeder Seite, die die Skelettmuskeln, Blutgefässe und neurovaskulären Verbindungswege mit ihren Knotenpunkten umfassten. Durch die Beobachtung der fortgeleiteten Empfindung (propagated sensation) in sensorischen Rezeptoren, hervorgerufen durch das Nadelstechen, wurden die Muskelverteilung und die neurovaskulären Verbindungen mit ihren Knotenpunkten beschrieben und aufgezeichnet. Die Entdeckung der von den inneren Organen zur Peripherie fortgeleiteten Schmerzen (referred pain) führte zum Verständnis der beherrschenden Rolle der Spinalsegmente. Die Verwendung solcher physiologischen Reaktionen ermöglichte die Entwicklung wiederholbarer Behandlungsregeln mittels des Konzepts von lokalen und lateralen (segmentale Dominanz), nahe gelegenen (proximalen) und Fernpunkten (longitudinale Effekte).

Donald E. Kendall, $\mathrm{PhD}$, OMD

6105 Lake Lindero Drive, Agoura Hills, CA 91301, USA

Tel. +1818 707-2924, Fax -3402

dekendall@earthlink.net 


\section{Mots-clés}

Thérapie des aiguilles - Acupuncture $\cdot$ Sensation propagée $\cdot$ Douleur projetée à partir d'un organe • Organisation longitudinale $\cdot$ Dominance segmentaire $\cdot$ Protocoles thérapeutiques

\section{Résumé}

Organisation spinale longitudinale associée à la dominance segmentaire dans la thérapie chinoise des aiguilles

Ce que les Chinois appelaient «thérapie des aiguilles» a été traduit en Occident sous le terme d'«acupuncture», introduit dans les années 30 , et se fonde sur d'impossibles idées de circulation d'énergie et de sang le long de méridiens invisibles. Le manque de compréhension des découvertes chinoises originelles qui avaient fait de l'insertion d'aiguilles une approche thérapeutique utile a rendu difficile la correction de ces fausses interprétations. En 1683, Willem ten Rhyne a été le premier à indiquer que les concepts chinois impliquaient la circulation sanguine continue et les nerfs. Les textes chinois les plus anciens sur la théorie des vaisseaux sanguins datent d'environ 168 à 150 av. J.-C. alors que la thérapie des aiguilles fut introduite dans le Classique interne de l'Empereur jaune (env. 200 à 100 av. J.-C.), accompagnée d'une description des nerfs. Cet ouvrage introduit les idées de l'organisation longitudinale du corps, associée à la dominance segmentaire essentielle à tous les vertébrés. Les Chinois divisaient le corps en 12 zones longitudinales de chaque côté, zones incluant les muscles squelettiques, les vaisseaux sanguins et les voies nodales neuro-vasculaires. La répartition des muscles et les voies nodales ont été établies à partir d'observations de sensation propagée chez des sujets sensibles répondant à l'insertion d'aiguilles. La découverte de la douleur projetée à partir d'un organe a entraîné la compréhension du rôle de la dominance segmentaire spinale. L'utilisation de ces caractéristiques a permis de développer des protocoles thérapeutiques pouvant être répétés et basés sur le concept de nœuds locaux et adjacents (dominance segmentaire), proximaux et distaux (effets longitudinaux).

\section{Introduction}

Public awareness and the clinical practice of 'acupuncture' has steadily increased in the West over the past 20-30 years. The ancient Chinese called it 'needle therapy (zhēnzhì 鍼 / 针 治)' and there is much confusion as to what this actually entails due to a lack of understanding the original Chinese concepts. Lay and medical practitioners typically view acupuncture as working by blood and energy circulation via invisible meridians first proposed by Soulié de Morant in 1939 and 1941 [1-3]. It should have been obvious at this time that blood only circulates in vessels as confirmed by William Harvey (1578-1657) in 1628 [4] along with Marcello Malpighi's (1628-1694) discovery of capillaries in 1661. The other serious flaw of Soulié de Morant's idea is the fact that 'energy' fueling biological function is 'a process' occurring within cellular mitochondria, and hence cannot circulate in anything [5]. It requires oxygen and glucose in cyclic enzymatic and electron transport chain oxidative reactions to convert adenosine diphosphate (ADP) to adenosine triphosphate (ATP); ATP then fuels cellular functions. These facts were already verified by Krebs in 1937 by elucidation of his citric acid cycle for which he won a Nobel Prize in 1955 [6].

The earliest first-hand report on acupuncture was provided by Willem ten Rhyne, MD (1647-1700), in 1683 based on a two-year stay in Japan $[7,8]$. He learned that Chinese concepts involved a continuing branching of outflowing arteries from the heart and like-mannered returnflowing veins back to the heart, and that nerves were also involved. The key Chinese discoveries which made needle therapy a useful treatment system was the longitudinal distribution of major blood vessels, related neurovascular nodes (jié 節 / 节, xué 穴), and skeletal muscles, mediated by spinal cord pathways; along with the discovery of organreferred pain involving peripheral nerve segmental dominance [9]. These features are common to all vertebrates.

\section{Ancient Chinese Discoveries}

All early humans, including the ancient Chinese, understood the critical need for the consumption of water (shuǐ 水) and nutrients (yíng 營/营), and the inhalation of atmospheric air (qì 氣/气) [9-12], now known to contain oxygen. They also had an appreciation for blood (xuè 血) being constrained within the blood vessels (mài 脈 / 脉) [9, 12-15]. The earliest Chinese mention of continuous blood circulation is found in the Guanzi: Essay on Water and Earth (ca. 375 BC) which considered: 'water as the blood and breath of earth in a similar manner to blood and breath circulation through blood vessels and muscles'. The oldest of the ancient Chinese blood vessel texts were retrieved in 1973 at Mawangdui, China, and date to 168 BC $[13,16]$. Similar vessel texts were also found in 1983 at Zhangjiashan in a tomb dated to 150 BC. These texts provide the first universal model of pathology based on the blood vessel theory. Most important of the ancient Chinese medicine texts, including the first information on needle therapy and neurovascular nodes, is the Huangdi Neijing (Yellow Emperor's Internal Classic) (ca. 200-100 BC), often referred to as the Neijing divided into the Suwen (SW) and Lingshu $(L S)$ volumes.

The early vessel texts described 11 vessels on each side of the body with 6 starting at the foot extremities and 5 with the hands. But, the character jing (經 / 经) is first applied to longitudinal blood vessels (jīngmài 經 脈) introduced in the Neijing. This is the same 'jing' used to denote classic texts, such as the Neijing itself, consisting of written text on vertical bamboo strips that are bound together in the form of 'longitudinal' scrolls. The Neijing provides a sophisticated understanding of cardiovascular circulation 
of blood, oxygen from inhaled air, nutrients noted to be absorbed by the small intestine veins $[9,17]$, as well as defensive substances (wèi 衛 / 卫) circulated out in the arterial supply to mount a defensive reaction and then drained back by means of lymphatic vessels to the subclavian veins. These discoveries derived from use of standard postmortem dissections to understand the cause of death. The Neijing also describes the brain, spinal cord, peripheral nerves, neural response to needling, and the phenomena of propagated sensation (PS) along longitudinal body pathways. The Neijing was also first to describe organ-referred pain $[9,18]$.

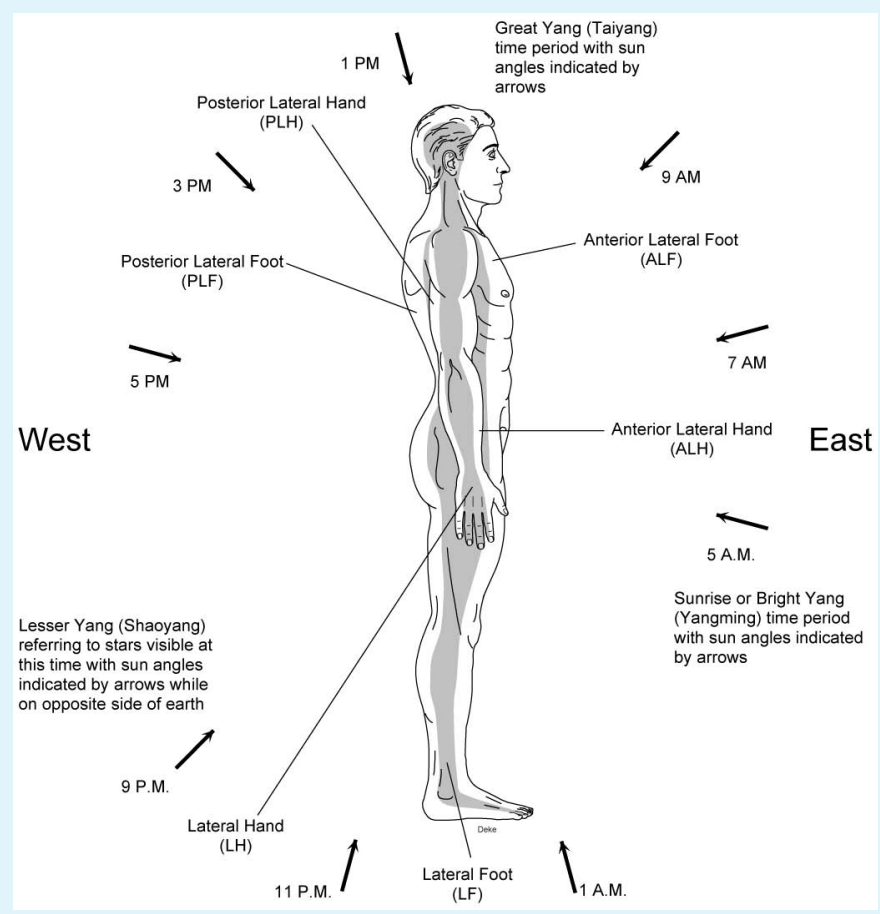

Fig. 1. Standard Chinese anatomical orientation scheme with respect to the sun (yáng 陽) position over a 24-h period showing longitudinal body regions for distribution of blood vessels, skeletal muscles, and neurovascular nodes.

\section{Longitudinal Organization with Segmental Dominance}

The ancient Chinese discovered longitudinal body organization which is common to all other animals (excluding jellyfish) with some modifications. This feature first appeared in unsegmented flatworms around 600-570 million years ago. Flatworms are the simplest animals to have a bilateral nervous system involving longitudinal nerve cords which form transverse collateral branches to supply sensory and motor nerve function at specific intervals along the body (segmental relationships). The chordates appeared 40-50 million years later but evolutionary changes from flatworms due to adapting to an aquatic environment caused them to swim inverted resulting in their central nervous system distributed on their dorsal aspect, first postulated by Anton Dohrn in $1875[19,20]$. Fish then appeared (510-439 million years ago) [21] and quickly diversified eventually giving rise to all subsequent vertebrates. The fundamental stages of longitudinal development and segmental dominance that is important to understanding Chinese needle therapy is clearly demonstrated by the study of embryology.

\section{Chinese Longitudinal View}

The Chinese anatomical notation scheme depicts a person facing East with the sun illuminating the body from different angles during the day and also when the sun is below the earth during the night (fig. 1). This scheme illuminates six longitudinal regions on the anterior lateral hand (ALH) and foot (ALF) during early morning; posterior lateral hand (PLH) and foot (PLF) during the afternoon; and lateral hand (LH) and foot (LF) during the time the sun is below the earth. These are the six lateral (yáng 陽 / 阳) regions of the body. The six medial (yīn 陰 / 阴) longitudinal body regions are the anterior medial hand (AMH) and foot (AMF); posterior medial hand (PMH) and foot (PMF); and medial hand (MH) and medial foot (MF). The medial time periods border their related lateral times (table 1). The medial hand and foot regions are considered
Table 1. Chinese and modern anatomical notation scheme for 12 longitudinal (jīng 經) body regions, related vessels, muscle distributions, circulation order, and organ-referred pain relationships

\begin{tabular}{|c|c|c|c|c|}
\hline $\begin{array}{l}\text { Chinese anatomical } \\
\text { divisions (pīnyīn) }\end{array}$ & $\begin{array}{l}\text { Longitudinal region, vessel, } \\
\text { and muscle distributions }\end{array}$ & $\begin{array}{l}\text { Vessel } \\
\text { type }\end{array}$ & $\begin{array}{l}\text { Somatovisceral rela- } \\
\text { tionship }^{\mathrm{a}}\end{array}$ & Time period \\
\hline Hand (Tàiyīn) & anterior medial hand (AMH) & artery & lungs (LU) & $3 a m-5$ am \\
\hline Hand (Yángmíng) & anterior lateral hand (ALH) & vein & large intestine (LI) & $5 \mathrm{am}-7 \mathrm{am}$ \\
\hline Foot (Yángmíng) & anterior lateral foot (ALF) & artery & stomach $(\mathrm{ST})$ & 7 am-9 am \\
\hline Foot (Tàiyīn) & anterior medial foot (AMF) & vein & pancreas (PN) & $9 \mathrm{am}-11 \mathrm{am}$ \\
\hline Hand (Shăoyīn) & posterior medial hand $(\mathrm{PMH})$ & artery & heart (HT) & $11 \mathrm{am}-1 \mathrm{pm}$ \\
\hline Hand (Tàiyáng) & posterior lateral hand (PLH) & vein & small intestine (SI) & $1 \mathrm{pm}-3 \mathrm{pm}$ \\
\hline Foot (Tàiyáng) & posterior lateral foot (PLF) & artery & bladder (BL) & $3 \mathrm{pm}-5 \mathrm{pm}$ \\
\hline Foot (Shăoyīn) & posterior medial foot (PMF) & vein & kidneys (KD) & $5 \mathrm{pm}-7 \mathrm{pm}$ \\
\hline Hand (Juéyīn) & medial hand $(\mathrm{MH})$ & artery & pericardium $(\mathrm{PC})$ & $7 \mathrm{pm}-9 \mathrm{pm}$ \\
\hline Hand (Shăoyáng) & lateral hand $(\mathrm{LH})$ & vein & internal membranes $^{\mathrm{b}}$ & $9 \mathrm{pm}-11 \mathrm{pm}$ \\
\hline Foot (Shăoyáng) & lateral foot (LF) & artery & gallbladder (GB) & $11 \mathrm{pm}-1 \mathrm{am}$ \\
\hline Foot (Juéyīn) & medial foot (MF) & vein & liver (LV) & $1 \mathrm{am}-3 \mathrm{am}$ \\
\hline
\end{tabular}

${ }^{a}$ Applies to neurovascular nodes along pathway-reflecting organ-referred pain.

'bānjiāo (三焦). 
to travel below the lateral regions where the pathways meet the body proper.

\section{Longitudinal Blood Vessel and Muscular Distributions} Superficial veins visible on the body surface appear to run longitudinally, but the Chinese performed postmortem dissections to trace out all the main longitudinal blood vessels correctly identifying outflowing arteries and matched return-flowing veins $[9,12]$. They identified the main internal vessels of the trunk including the aorta (chōngmài 衝 / 冲 脈) supplying the internal organs and the vena cava (rènmài 任脈) (and portal vein) draining the organs, along with the veins draining the posterior body cavity including the azygos, hemiazygos, and lumbar veins (dūmài 督脈). All major arteries and veins supplying the face, head, neck, trunk, and extremities were mapped out for the 12 anatomical body regions of each side of the body. This involved three major arteries supplying each of the hands and feet which were then drained by three related veins, starting with the hand and followed by the foot vessels (table 1, columns 2 and 3) [9, chapter 9-11].

Twelve longitudinal muscle (jīngjīn 經筋) distributions were mapped out within the anatomical body regions on each side of the body (fig. 1, table 1). Muscles were considered to comprise the external body and not related to the internal organs. Muscle pathways were mapped out for each of the 12 distributions, starting at the insertion sites on the toes and fingers and then describing the origin of each muscle. This process was continued up the body until all the muscles were described for the entire body (fig. 2) [9, chapter 12]. Only three muscles were actually given names.

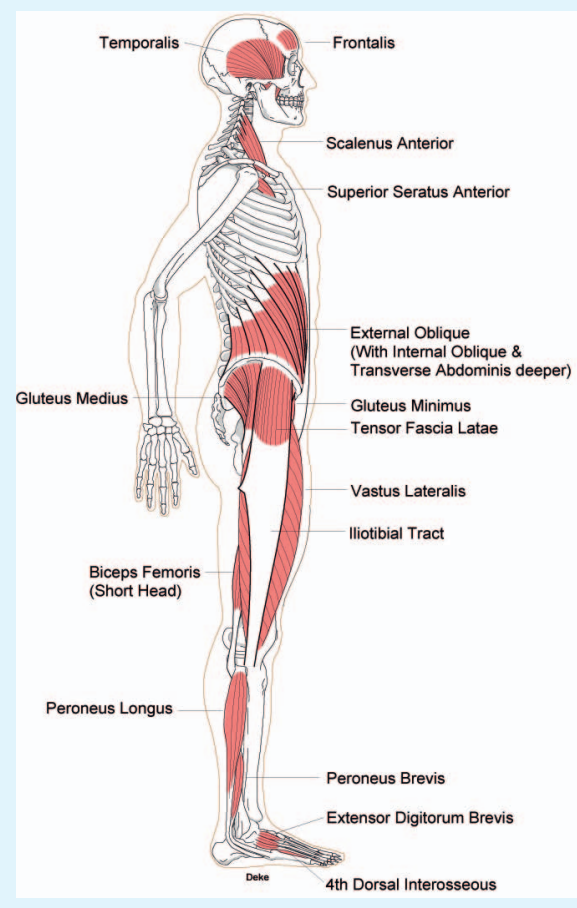

Fig. 2. One of 12 longitudinal muscle pathways on each side of the body involving muscles of the lateral foot (LF) body region as noted in the Huangdi Neijing, LS 13.

\section{Chinese Understanding of Nerves}

Willem ten Rhyne (1683) provided the first mention that Chinese medicine involved nerves [7,8]. The Neijing and other Chinese works indicate they understood nerves and the phenomena of PS $[9,12]$. Their terminology describing nerves is consistent with modern usage [22]. They used the character suí (髓) to denote nerves and the spinal cord and when used with the character jí (脊) for backbone, it referred to spinal nerves [9, pp 51-53]. Europe considered suǐ 髓 to mean 'marrow' consistent with terminology of the time that referred to the spinal cord as 'spinal marrow'.

The introduction of sui 髓 to mean nerves is provided by the Yellow Emperor in a discussion of embryonic and fetal development in response to being asked about blood vessel development in LS 10 as follows: 'Life for the human first starts when the reproductive essence combines (father's sperm unites with the mother's egg). As result of this conception the brain and nerves start to form and the bones develop to provide a framework for the body. The blood vessels form to circulate nutrients and the muscles develop to make the body strong. The flesh develops to form the body trunk and the skin becomes firm and the hair can grow long'.

Further clarification that sui (髓) means nerves is provided in $S W 11$ on the question if the brain and nerves may be considered viscera where the Yellow Emperor asks: 'I have heard from some physicians that perhaps the brain and the nerves are considered to be viscera ... Qi Bo directly replied: The brain, nerves, bones, blood vessels, gallbladder, and uterus are six organs generated by the earth's environment'.

In addition, all nerves were considered to be connected to the brain as noted in SW 10: 'All blood vessels relate to the eyes, all nerves join the brain, the muscles and tendons belong to the joints, blood belongs to the heart, essential breath belongs to the lungs and these provide function to the four extremities and eight articulations from morning to night'.

The character shén (神) can mean: vitality, mind, miraculous effect, or spirit. The term shénqì 神氣 is used to indicate nerve signals and modern names for nerves and the spinal cord are basically consistent with terminology of the Neijing. Possible involvement of nerves in the function of neurovascular nodes is provided in LS 1: 'That which we call nodes are the places that vitality (nerve) signals transmit inward and outward (efferent and afferent nerve signals), and is not just skin, flesh, muscles, and bones'.

\section{Propagated Sensation to Segregate Neurovascular Nodes} The longitudinal vessels give rise to collateral vessels (luòmài 絡 / 络脈) which then supply fine vessels (sūnmài 孫 / 孙脈) consisting of arterioles, capillaries, venules, and related nerves to the superficial body and skin. This 
basically covers the entire superficial body, but some of these nodes have more fine vessels and nerves than other sites. These are the more reactive spots on the body that the Chinese identified as neurovascular nodes for needling. The challenge for the ancient practitioners was to determine which nodes were related to the 12 specific longitudinal anatomical body regions. Fortunately, they had discovered that sensitive responders could actually describe the pathways of needle response as a PS [9, pp 52-53]. It may have taken centuries to identify the present-day listings of useful neurovascular nodes. The Neijing discusses the clinical utility in stimulating PS and China has conducted significant research to confirm these results $[9$, pp 268-272; 23]. Needle-activated PS results in muscle action potentials (MAP) along the body which provided a means to identify the muscles within each longitudinal distribution. As example, needling the node Lateral Foot 41 (Zulinqi) overlying the 4th dorsal interosseous muscle on the foot produces PS in sensitive responders that travels along the lateral foot muscle distribution (fig. 2) producing MAP in the temporalis muscle.

\section{Organ-Referred Pain and Segmental Dominance}

Use of standard postmortem examinations allowed the Chinese to correlate previously determined painful body areas with postmortem organ pathology. Identification of referred pain areas provided useful clues about which organ to treat as noted in LS 66: 'The areas of pain should be carefully examined in order to determine which organ is involved. The conditions may be either excess or deficient. In case of deficiency, it should be regulated by mending, in case of excess, it should be regulated by draining off'.
The next step was to determine which specific longitudinal vessel traversed each of the organ-referred pain areas, with some covering more than one area. This eventually led to associating each superficial longitudinal vessel pathway with specific organ-related painful areas noted in LS 73: 'With respect to the five viscera and six bowels, careful examination of their referred pain, both on the left and right sides, and the upper and lower portions of the body, permits understanding if it is a cold or warm condition and what longitudinal vessel is involved. The skin can be further examined to determine if it is either cold or warm, sliding or retarded, to determine the nature of the painful condition. The area above and below the diaphragm should be examined in locating the disease'.

The longitudinal vessels were already named by their anatomical body regions (fig. 1 and table 1, column 2) and were then associated with somatovisceral relationships involving specific internal organs (table 1, column 4). Soulié de Morant mistakenly named his meridians by the organ names causing all the neurovascular nodes on each pathway having an organ prefix, giving the false impression that every node was useful for treating conditions for that organ [3]. In fact, only a few nodes along any neurovascular pathway are useful in treating conditions of its related somatovisceral organ. But, the most important aspect of these relationships was the recognition of spinal segmental dominance. Basically, all the sensory information stimulated by needling the superficial body is conveyed to the spinal cord at specific segmental levels, or brain regions in the case of cranial nerves serving the head and face.
Table 2. Special related visceral front recruitment (mù 募) and back communication (shū 輸) nodes of the anterior and posterior trunk regions, with nominal spinal segmental levels, and corresponding internal organ innervation

\begin{tabular}{|c|c|c|c|c|c|}
\hline \multirow[t]{2}{*}{ Organ } & \multicolumn{2}{|l|}{ Front recruitment (mù) } & \multicolumn{2}{|l|}{ Back communication (shū) } & \multirow{2}{*}{$\begin{array}{l}\text { Internal organ } \\
\text { innervation }\end{array}$} \\
\hline & nodes & spinal level & nodes & spinal level & \\
\hline LU & Zhongfu (AMH 1) & $\mathrm{T} 2$ & Feishu (PLF 13) & T3-4 & $\mathrm{T} 1-\mathrm{T} 7$ \\
\hline $\mathrm{PC}$ & Tanzhong (RN 17) & $\mathrm{T} 4$ & Jueyinshu (PLF 14) & $\mathrm{T} 4-5$ & $\mathrm{~T} 1-\mathrm{T} 5$ \\
\hline HT & Juque (RN 14) & T6 & Xinshu (PLF 15) & T5-6 & $\mathrm{T} 1-\mathrm{T} 5$ \\
\hline LV & Qimen (MF 14) & T5 & Ganshu (PLF 18) & T9-10 & T5-T9 \\
\hline GB & Riyue (LF 24) & T6 & Danshu (PLF 19) & T10-11 & T6-T9 \\
\hline $\begin{array}{l}\text { PN } \\
\text { Spleen }\end{array}$ & Zhangmen (MF 13) & $\mathrm{T} 8$ & Yi/Pishu (PLF 20) & T11-12 & $\begin{array}{l}\text { T5-T11 } \\
\text { T6-T9 }\end{array}$ \\
\hline ST & Zhongwan (ALF 12) & $\mathrm{T} 7$ & Weishu (PLF 21) & $\mathrm{T} 12$ & T5-T10 \\
\hline $\mathrm{KD}$ & Jingmen (LF 25) & $\mathrm{T} 10$ & Shenshu (PLF 23) & $\mathrm{L} 2$ & T10-L1 \\
\hline LI & Tianshu (ALF 25) & T9-10 & Dachangshu (PLF 25) & L4 & T6-L2 \\
\hline SI & Guanyuan (RN 4) & T11-12 & Xiaochangshu (PLF 27) & S1 & T6-L1 \\
\hline BL & Zhongji (RN 3) & $\mathrm{T} 12$ & Pangguanshu (PLF 28) & S2 & T11-L2; S2-S4 ${ }^{\mathrm{a}}$ \\
\hline $\begin{array}{l}{ }^{\mathrm{a}} \mathrm{Has} \text { bo } \\
\mathrm{LU}=\mathrm{L} \\
\mathrm{LI}=\text { liv }\end{array}$ & $\begin{array}{l}\text { pathetic and parasym } \\
\mathrm{C}=\text { pericardium; } \mathrm{HT} \\
=\text { small intestine; } \mathrm{BL}=\end{array}$ & $\begin{array}{l}\text { pathetic in } \\
=\text { heart; LV } \\
=\text { bladder. }\end{array}$ & $\begin{array}{l}\text { by spinal nerves. } \\
\mathrm{B}=\text { gallbladder; } \mathrm{PN}=\end{array}$ & +2 & $\mathrm{KD}=$ kidneys; \\
\hline
\end{tabular}




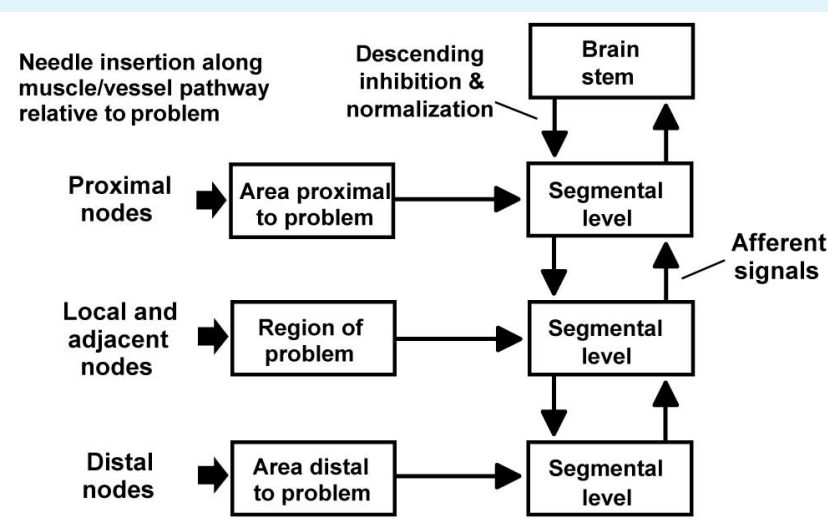

Fig. 3. Schematic of neurovascular node selection that are local and adjacent (LA) to the problem area that integrate at same or adjacent spinal nerve levels, along with proximal $(\mathrm{P})$ nodes that integrate at the same or higher segmental region, and the distal (D) nodes on the extremity associated with the affected muscle distribution, to direct descending restorative processes.

The Chinese also identified specific nodes on the anterior body called recruitment (mù 募) nodes and on the back called communication (shū 輸/ 输) nodes that were assigned to specific internal organs (table 2). Recruitment nodes were considered to stimulate organ substance (yin 陰) while the communication nodes stimulated organ function (yáng 陽), both used to restore physiological balance. Although the recruitment nodes are distributed on each side of the body proper they nearly overlie their associated organ on one side or the other. So there is a good correspondence between the spinal level of these nodes (table 2, column 3) and spinal integration for level of nerves supplying the related internal organ (table 2, column 6). The back communication nodes are located 1.5 Chinese body inch on each side of the spine at the lower border of each vertebrae starting with T3 and continuing down to the level of the fourth posterior sacral foramen. There is also a reasonably good correlation with the back communication nodes (table 2, column 4), except these are located at fixed segmental levels which show some mismatch at the lower spinal levels (table 2, column 6). Several studies have confirmed the convergence of somatic node and visceral afferent neurons [9, pp 272-276] for the heart [24, 25], stomach [26, 27], bladder [28], and gallbladder [29].

\section{Application to Treatment Protocols}

Discovery of longitudinal spinal organization and segmental dominance provided the Chinese enough information to devise rational and repeatable needle therapy protocols. It is not clear if they had a full understanding of the contribution of the tissue and immune responses to needling along with the brain in mediating pain relief, reducing inflammation, eliminating pathogenic factors, restoring blood flow, restoring muscular function, relieving emotional stress, normalizing internal organ function, and restoring physiological balance (zhèngqì 正 氣). They devised treatment strategies involving local and adjacent nodes associated with respect to the location of the problem, along with proximal nodes, and then distal nodes on the appropriate limb.

Afferent $\mathrm{A} \delta$ and $\mathrm{C}$ nerve fiber response to needling at these sites integrate at the same or adjacent spinal segmental levels, and directed to crossed fibers of the spinal cord anterior lateral tract (ALT) on the opposite side. The ascending ALT signals are directed to specific nuclei of the brainstem, including the dorsal raphe nuclei that activate descending enkephalin containing serotonergic fibers on the same side that was needled. This results in the release of enkephalin onto interneurons, at the same segmental level of the initiating afferent needle response, which then mediates inhibition of pain along with the wide range of effects noted above (fig. 3 ) [9, chapter 14, 15; 30-32].

\section{Local and Adjacent Nodes}

Chinese practitioners understood that treatments initially considered neurovascular nodes within the location of where the problem is reflected on the body, be it an internal organ or musculoskeletal condition, involving the use of local and adjacent nodes. In the case of an elbow condition, nodes would be selected around and near the elbow associated with affected muscle or adjacent muscle distribution.

\section{Proximal Nodes}

These nodes are selected that are usually at a higher spinal integration site than the local and adjacent nodes selected to address the presenting problem. Proximal nodes are often located on the posterior regions of the lumbar, thoracic, or shoulder, upper back, or upper neck depending on the prime location of the problem. These nodes enhance the therapeutic effect of the local and adjacent node or spread the restorative effects to a slightly higher level along the spinal cord. In the case of an elbow problem, these nodes would be selected on the shoulder, upper back, or upper neck. However, with sacral, lumbar, or thoracic problems, the proximal nodes are usually represented by the local and adjacent nodes on the back.

\section{Distal Nodes}

These nodes are unique in that they are typically located on the hands or feet which have a high density of afferent sensory nerve fibers. As a consequence, distal nodes provoke strong responses. Distal nodes are selected on the affected extremity associated with the prime longitudinal muscle or vessel distribution involved in the presenting problem. Distal nodes may also be selected on adjacent distributions. 


\section{Conclusions}

The Huangdi Neijing (ca. 200-100 BC) confirms that the Chinese had a keen understanding of anatomy and physiology, resulting in the development of 'needle therapy'. Discovery of ten Rhyne's dissertation in the early 1800s sparked an interest in acupuncture in Europe and America. One hundred years later, Soulié de Morant translated the character qì (氣) for 'air and inhaled breath' to mean 'energy' (for lack of a better word) and translated 'longitudinal blood vessels (jīngmài 經 脈)' to be 'invisible meridians which circulate blood and energy'. These ideas resonated with many lay and medical professionals intrigued by simplified metaphysical concepts which were falsely promoted as original Chinese concepts.

Researchers have been looking for 'invisible meridians' while the Chinese were actually describing the deeper underlying longitudinal blood vessels and related nerves supplying the superficial neurovascular nodes (jié 節) by collateral branches. Therefore, neurovascular nodes assigned to specific longitudinal pathways are not directly connected to each other in the superficial tissue regions. Afferent responses to needling are directed to the ALT on the opposite side, as well as being conducted up and down the dorsal lateral funiculus (DLF) on the same side being needled. When threshold conditions permit, PS can be provoked, subjectively sensed, and objectively measured on the superficial skin. Purpose of DLF activation is to direct descending restorative response to the same segmental levels that were needled.

Use of the term 'meridian' needs to be replaced with science-based terminology that conveys the correct Chinese concept. This could include using 'neurovascular nodal pathways' or just 'nodal pathways'. Furthermore, the word 'acupuncture' is basically described in terms of metaphysical concepts and its usage should eventually be phased out in favour of physiologically based terms such as 'needle therapy' as consistently used in China.

\section{Disclosure Statement}

There are no conflicts of interest in this article.

\section{References}

1 Soulié de Morant G: L'Acuponcture chinoise. Tome I Lénergie (Points, Méridiens, Circulation). Paris, Mercure de France, 1939.

2 Soulié de Morant G: L'Acuponcture chinoise. Tome II Le maniement de l'énergie. Paris, Mercure de France, 1941

3 Zmiewski P (ed): Georges Soulié de Morant, Chinese Acupuncture (Lacuponcture Chinoise). Translated by Grinnell L, Jeanmougin C, Leveque M. Brookline, MA, Paradigm, 1994.

4 Harvey W: Exercitatio anatomica de motu cordis et sanguinis in animalibus. Francofurti (Frankfurt), 1628. The first English text, 'Anatomical exercises on the motion of the heart and blood in animals', translated and edited by Geoffrey Keynes. London, 1653.

$\checkmark 5$ Kendall DE: Energy-meridian misconception of Chinese medicine. Schweiz Zschr Ganzheitsmedizin 2008;20:112-117.

6 Krebs HA: The history of the tricarboxylic acid cycle. Perspect Biol Med 1970;14:154-170.

7 Wilhelmi ten Rhyne MD. and c. TransisalanoDaventriensis Dissertatio de arthritide: Mantissa schematica: De acupunctura: et Orationes tres, I. De chymiae ac botaniae antiquitate and dignitate: II. De physiognomia: III. De monstris / Singula ipsius authoris notis illustrata. London, imp. R. Chiswell\#ad insigne Rosae Corona, 1683.

$\checkmark 8$ Carrubba RW, Bowers JZ: The Western world's first detailed treatise on acupuncture: Willem ten Rhyne's De Acupunctura. J Hist Med Allied Sci 1974;29:371-398.

9 Kendall DE: Dao of Chinese Medicine: Understanding an Ancient Healing Art. London, Oxford University Press, 2002.

10 Wieger SJ: Chinese Characters: Their Origin, Etymology, History, Classification and Signification. New York, Dover, 1965.
11 Mathews RH: Mathews' Chinese-English Dic tionary. Shanghai, China Inland Mission and Presbyterian Mission Press, 1931

12 Schnorrenberger CC: Anatomical Roots of Chinese Medicine and Acupuncture. J Chin Med 2008;19:35-63.

13 Harper DJ: Early Chinese Medical Literature: The Mawangdui Medical Manuscripts. London, Kegan Paul International, 1998.

14 Unschuld PU: Huang Di Nei Jing Su Wen: Nature, Knowledge, Imagery in an Ancient Chinese Medical Text. Berkeley, University of California Press, 2003.

15 Tessenow H, Unschuld PU: A Dictionary of the Huang Di Nei Jing Su Wen. Berkeley, University of California Press, 2008.

$16 \mathrm{Ma}$ JX: Acupuncture and moxibustion; in Institute of the History of Natural Sciences: AncientChina's TechnologyandScience.Beijing, Foreign Language Press, 1983, pp 345-351.

17 Cruikshank C: The Anatomy of the Absorbing Vessels of the Human Body, ed 2. London, Printed for G. Nicol, Book Seller to his Majesty, Pall-Mall, 1790.

18 Head H: On the disturbances of sensation, with special reference to the pain of visceral disease. Brain (Oxford) 1893;16:1-133.

19 Dohrn A: Der Ursprung der Wirbelthiere und das princip des Functionswechsels. Leipzig, Wilhelm Engelmann, 1875.

20 Denes AS, Jékely G, Steinmetz PRH, Raible F, Snyman H, Prud'homme B, Ferrier DEK, Balavoinev G, Arendt D: Molecular architecture of annelid nerve cord supports common origin of nervous system centralization in bilateria. Cell 2007;129:277-288.

21 Nelson JS: Fishes of the World, ed 3. New York, John Wiley and Sons, 1994.
22 Cui YL: The Chinese-English Medical Dictionary. Beijing, The People's Medical Publishing House, 1987.

23 Yan JQ, Wang KM, Hou ZL: The observation on the general properties of the acupoint muscle action potential (article in Chinese). Zhen Ci Yan Jiu (Acupuncture Research) 1987;12:138, 144-145.

24 Tao ZL, Li RW: The segmental distribution of sympathetic afferent neurons of the heart, cardiac nerve, and projection of the cardiac nerve to the central nervous system (article in Chinese). Zhen Ci Yan Jiu (Acupuncture Research) 1993;18:257-261.

25 Tao ZL, Li RW, Li CH: The Segmental Distribution of the Afferent Neurons of the 'Neiguan' Point. The Second National Symposium on Acupuncture and Moxibustion and Acupuncture Anesthesia. Beijing, Foreign Languages Printing House, 1984, p 491.

26 Tao ZL, Wang LP, Li RW, Zhang ZP, Xi SY: The Segmental Distribution of the Afferent Neurons of the 'Zusanli' Point and the Stomach-HRP Method. The Second National Symposium on Acupuncture and Moxibustion and Acupuncture Anesthesia. Beijing, Foreign Languages Printing House, 1984, p 491.

27 Tao ZL, Wang LP, Zhang ZP, Li CH: Application of the HRP Method to Explore the Segmental Distribution of the Sympathetic Afferent of the Stomach (Anterior Wall, Posterior Wall, Pylorus and Cardia). The Second National Symposium on Acupuncture and Moxibustion and Acupuncture Anesthesia. Beijing, Foreign Languages Printing House, 1984, p 489. 
28 Li JH, Qin BZ, Li HM, Lu SW: The Segmental Distribution of Visceral (Urinary Bladder) and Somatic (Sciatic Nerve) Afferent Fibers and the Relation between Their Terminal Distributions in Spinal Cord of Rabbit a Study with HRP Retrograde and Transganglionic Tracing Techniques. The Second National Symposium on Acupuncture and Moxibustion and Acupuncture Anesthesia. Beijing, Foreign Languages Printing House, 1984, p 484.

29 Tao Z, Jin Z, Ren W: Segmental distributions of sensory neurons of the 'ganshu', 'pishu', 'liangmen', 'qimen' points and the gallbladder (Chinese). Zhen Ci Yan Jiu (Acupuncture Research) 1991;16:61-65.

30 Macdonald AJR: Acupuncture's non-segmental and segmental analgesic effects: the points of meridians; in Filshie J, White A (ed): Medical Acupuncture, a Western Scientific Approach. London, Churchill Livingstone, 1998, pp 83-104.

31 Bekkering R, van Bussel R: Segmental acupuncture; in Filshie J, White A (ed): Medical Acupuncture, a Western Scientific Approach. London, Churchill Livingstone, 1998, pp 105-135.

32 White A, Cummings M, Filshie J: An Introduction to Western Medical Acupuncture. London, Churchill Livingstone, 2008. 